\title{
JNPH
}

Volume 5 No. 1 (Juli 2017)

(C) The Author(s) 2017

\section{HUBUNGAN OBESITAS DENGAN KEJADIAN HIPERTENSI DI POLIKLINIK JANTUNG RSUD DR.M.YUNUS BENGKULU TAHUN 2016}

\author{
THE CORRELATION OF OBESITY WITH HYPERTENSION EVENTS AT HEART \\ POLICLINIC IN DR.M.YUNUS HOSPITAL BENGKULU 2016
}

\author{
DES METASARI, NOVI LASMADASARI \\ SEKOLAH TINGGI ILMU KESEHATAN DEHASEN BENGKULU \\ AKADEMI KESEHATAN SAPTA BAKTI BENGKULU \\ Email: DESMETAHERI@GMAIL.COM, LANOVI.NL@GMAIL.COM
}

\begin{abstract}
ABSTRAK
Penyakit kardiovaskuler merupakan problema kesehatan utama di negara maju dan berkembang, sehingga menjadi penyebab utama kematian nomor satu di dunia begitu juga di Indonesia. Di Indonesia angka kejadian hipertensi cukup tinggi. Menurut data Riset Kesehatan Dasar (Riskesdas) angka kejadian hipertensi pada lima tahun terakhir sebanyak 31,7\%, Ada beberapa penyebab hipertensi diantaranya adalah kegemukan. Data yang diperoleh dari Rumah sakit DR.M.Yunus Bengkulu pada tahun 2015 periode Januari s/d September jumlah penderita hipertensi 943 orang dari 1211 pasien yang berkunjung. Tujuan penelitian ini adalah melihat hubungan obesitas dengan kejadian hipertensi. Jenis penelitian deskriptif dimana pengumpulan data dalam waktu yang bersamaan. Populasi dalam penelitian ini adalah pasien yang datang berobat ke Poliklinik Jantung RSUD Dr.M.Yunus Bengkulu pada tahun 2016. Penelitian ini dilaksanakan pada tanggal 12 Mei 2016 s.d 24 Juni 2016 yakni sebanyak 100 orang diambil dengan teknik accidental sampling. Hasil penelitian menunjukkan bahwa Sebagian besar responden (67.0\%) mengalami hipertensi. Sebagian kecil responden (12.0\%) mengalami obesitas. Ada hubungan antara kejadian hipertensi dengan obesitas dengan nilai $P: 0,000$. Disarankan kepada pihak rumah sakit diharapkan dapat meningkatkan program promosi kesehatan yang lebih baik lagi kepada pasien maupun kepada keluarga pasien mengenai faktorfaktor penyebab hipertensi terutama obesitas, sehingga pasien akan berusaha mengatur diit yang sehat dan menjaga kestabilan BB, petugas hendaknya selalu mengingatkan penderita hipertensi untuk selalu mengontrol tekanan darahnya setiap hari.
\end{abstract}

Kata kunci : hipertensi, obesitas

\begin{abstract}
Cardiovascular disease is a major health problem in developed and developing countries, making it the leading cause of death number one in the world as well as in Indonesia. In Indonesia the incidence of hypertension is high enough. According to the data of Basic Health Research (Riskesdas) the number of hypertension events in the last five years as many as $31.7 \%$, There are several causes of hypertension such as obesity. Data obtained from DR.M.Yunus Bengkulu Hospital in 2015 from January to September the number of hypertension 943 people from 1211 patients who visit. The purpose of this study is to look at the relationship of obesity with the incidence of hypertension. Type of descriptive research
\end{abstract}


where data collection at the same time. The population in this study were patients who came to the Heart Polyclinic RSUD Dr.M.Yunus Bengkulu in 2016. This study was conducted on May 12, 2016 until June 24, 2016 as many as 100 people taken by accidental sampling technique. The results showed that most respondents $(67.0 \%)$ had hypertension. A small percentage of respondents $(12.0 \%)$ were obese. There is a relationship between the incidence of hypertension with obesity with a value of P: 0.000 . It is suggested that the hospital is expected to improve the health promotion program better to the patient and to the patient's family about the factors causing hypertension, especially obesity, so that patient will try to arrange healthy diet and keep the stability of $\mathrm{BB}$, the officer should always remind the hypertension patient to always control her blood pressure every day.

Keywords: hypertension, obesity

\section{PENDAHULUAN}

Penyakit kardiovaskuler merupakan problema kesehatan utama di negara maju dan berkembang, sehingga menjadi penyebab utama kematian nomor satu di dunia begitu juga di Indonesia, baik bagi laki - laki maupun perempuan. Data dari World Health Organization (WHO) tahun 2012 menyebutkan sekitar 17,5 juta orang meninggal karena penyakit kardiaovaskuler atau 30\% dari kematian diseluruh dunia, salah satu penyakit kardiovaskuler tersebut adalah hipertensi.

Menurut catatan dari WHO tahun 2011 ada angka kematian karena hipertensi di Indonesia satu milyar orang menderita hipertensi dan dua pertiga berada di negara negara berkembang seperti Indonesia, bila tidak dilakukan dengan upaya yang cepat dan tepat jumlah akan terus bertambah dan diprediksi pada tahun 2025 sebanyak 29\% atau 1,6 milyar orang diseluruh dunia menderita hipertensi, sedangkan di Indonesia angka kejadian hipertensi cukup tinggi.

Menurut data Riset Kesehatan Dasar (Riskesdas) angka kejadian hipertensi pada lima tahun terakhir sebanyak 31,7\%, sementara kasus hipertensi yang belum berhasil terdiagnosa juga masih banyak yakni mencapai 76\%. Ada beberapa penyebab hipertensi diantaranya adalah kegemukan. Berat Badan seseorang akan mengakibatkan obesitas berhubungan erat dengan distribusi lemak tubuh. Penimbunan lemak di tubuh akan membuat terjepitnya pembuluh darah akibat bantalan lemak, kondisi lumen pembuluh darah yang menyempit ini akan memperkencang aliran darah dan kondisi ini akan mempercepat denyut jantung dan denyut nadi sehingga peningkatan aktivitas jantung ini di manifestasikan dengan peningkatan tekanan darah. Tipe obesitas menurut pola distribusi lemak tubuh dapat dibedakan menjadi obesitas tubuh bagian atas (upper body obesity) dan obesitas tubuh bagian bawah (lower body obesity) (Ardiansyah, 2012).

Penelitian yang dilakukan oleh Yufita Yeni dkk tahun 2009 tentang faktor-faktor yang berhubungan dengan kejadian hipertensi pada Wanita Usia Subur di Puskesmas Umbulharjo I Yogyakarta, hasil penelitian menunjukkan faktor yang yang berhubungan dengan hipertensi adalah stress dan peningkatan berat badan dengan nilai $P$ : 0,007 Data yang diperoleh dari Rumah sakit DR.M.Yunus Bengkulu pada tahun 2014 di poliklinik Jantung terdapat 1230 kasus hipertensi dari 1546 pasien yang berkunjung, pada tahun 2015 jumlah pasien hipertensi meningkat menjadi 1320 dari 1590 orang pasien yang berkunjung, pada tahun 2016 periode Januari s/d September jumlah penderita hipertensi 943 orang dari 1211 pasien yang berkunjung (Medical Record RSUD DR. M.Yunus Bengkulu).

Berdasarkan di atas dapat dilihat masih tingginya angka kejadian hipertensi, sehingga dapat dirumuskan masalah penelitian "Apakah ada hubungan antara kejadian hipertensi dengan obesitas di poliklinik Jantung RSUD Dr. M. Yunus Bengkulu tahun 2016?" 
Tujuan penelitian ini adalah diketahuinya hubungan obesitas dengan kejadian hipertensi di poliklinik Jantung RSUD Dr. M. Yunus Bengkulu tahun 2016. Tujuan Khusus diketahuinya gambaran kejadian Hipertensi di poliklinik Jantung RSUD Dr. M.Yunus Bengkulu tahun 2016, diketahuinya gambaran obesitas di poliklinik Jantung RSUD Dr. M. Yunus Bengkulu tahun 2016 dan diketahuinya hubungan obesitas dengan kejadian hipertensi di poliklinik Jantung RSUD Dr. M. Yunus Bengkulu tahun 2016.

Manfaat penelitian diharapkan dapat menjadi acuan bagi pihak rumah sakit dalam menangani pasien dengan hipertensi, dengan memberikan penyuluhan pada ibu untuk menjaga kenaikan berat badan agar tetap berada pada ambang batas kenormalan. Penelitian ini dapat menjadi referensi bagi pihak akademis dan sebagai bahan bacaan yang berhubungan dengan obesitas dan hipertensi.

\section{METODE PENELITIAN}

Penelitian ini jenis penelitian deskriptif analitik dengan menggunakan metode penelitian cross sectional dimana pengumpulan atau pengukuran terhadap variabel dilakukan sekali dalam waktu bersamaan (Notoatmodjo, 2005). Mengukur obesitas peneliti menimbang $\mathrm{BB}$ dan mengukur TB pasien sehingga didapatkan Indeks Massa Tubuh, sedangkan data sekundernya menggunakan status pasien untuk melihat adanya variabel kejadian hipertensi.

Sampel dalam penelitian ini adalah seluruh pasien yang berkunjung ke poliklinik Jantung RSUD Dr. M. Yunus Bengkulu priode Januari s.d April tahun 2016 yang berjumlah 100 orang yang diambil dengan teknik accidental sampling.

Penelitian ini dilakukan di poliklinik Jantung RS.Dr M.Yunus Bengkulu pada tanggal 12 Mei 2016 s.d 24 Juni 2016 dengan tahapan penelitian sebagai berikut: pengumpulan data setelah mendapatkan izin dari rumah sakit umum Dr. M. Yunus
Bengkulu, peneliti mulai melakukan penelitian dengan cara menimbang $\mathrm{BB}$ dan mengukur TB untuk mengambil data primer dan untuk mengambil data sekunder peneliti melihat ke catatan medis di status pasien setelah data terkumpul data kemudian diolah dengan sistem komputer menggunkan SPSS 17. Untuk memudahkan pengolahan data, data yang terkumpul berdasarkan pedoman penskoran menurut cara ukur dan hasil ukur pada definisi operasional pengolahan data melalui beberapa tahap pengolahan data: Mengedit (Editing), pengkodean (Coding), entry data, pembersihan data (Cleaning), analisis Data yang terdiri dari analisa univariat dan analisa bivariat.

\section{HASIL PENELITIAN}

Data yang diperoleh kemudian diolah menggunakan program komputer dengan SPSS 17, dari hasil pengolahan data maka dilakukan analisis Univariat untuk mengetahui gambaran distribusi frekuensi masing - masing variabel penelitian dan analisis Bivariat untuk mengetahui hubungan antar variabel yaitu variabel independen (obesitas) dengan variabel dependen (kejadian Hipertensi), adapun hasil penelitiannya adalah : Analisis ini dilakukan untuk melihat distribusi frekuensi obesitas dan hubungan obesitas dengan kejadian Hipertensi. Adapun hasil analisisnya sebagai berikut:

Tabel 1 Distribusi frekuensi kejadian hipertensi dan obesitas di Poliklinik Kebidanan RSUD Dr.M.Yunus Bengkulu tahun 2016

\begin{tabular}{lcc}
\hline $\begin{array}{c}\text { Kejadian } \\
\text { Hipertensi }\end{array}$ & F & $\mathbf{\%}$ \\
\hline Hipertensi & 67 & 67 \\
\hline Tidak Hipertensi & 33 & 33 \\
\hline Jumlah & 100 & 100 \\
\hline Obesitas & & \\
\hline Obesitas & 12 & 12 \\
\hline Tidak Obesitas & 88 & 88 \\
\hline Jumlah & 100 & 100 \\
\hline Sumber : Data penelitian 2016 &
\end{tabular}

Sumber : Data penelitian 2016 
Berdasarkan tabel 1 dapat diketahui bahwa sebagian besar responden $(67.7 \%)$ tidak mengalami hipertensi, sebagian kecil responden $(88 \%)$, tidak mempunyai riwayat obesitas.

Tabel 2 Hubungan obesitas dengan kejadian hipertensi dan obesitas di Poliklinik Kebidanan RSUD Dr.M.Yunus Bengkulu tahun 2016

\begin{tabular}{|c|c|c|c|c|c|c|}
\hline \multirow[t]{3}{*}{ Obesitas } & \multicolumn{4}{|c|}{ Kejadian Hipertensi } & \multicolumn{2}{|c|}{ Total } \\
\hline & \multicolumn{2}{|c|}{ Hipertensi } & \multicolumn{2}{|c|}{ Tidak Hipertensi } & \multirow[t]{2}{*}{$\mathrm{F}$} & \multirow[t]{2}{*}{$\%$} \\
\hline & $\mathrm{F}$ & $\%$ & $\mathrm{~F}$ & $\%$ & & \\
\hline Obesitas & 11 & 91.7 & 1 & 8.3 & 12 & 100 \\
\hline $\begin{array}{c}\text { Tidak } \\
\text { Obesitas }\end{array}$ & 56 & 63.3 & 32 & 36.4 & 88 & 100 \\
\hline
\end{tabular}

Sumber : Data penelitian 2016

Tabel 2 di atas menunjukkan bahwa dari 12 responden yang mengalami obesitas terdapat 11 responden $(91.7 \%)$ yang mengalami hipertensi dan dari 88 responden yang tidak obesitas terdapat 56 responden (63.3\%) yang mengalami hipertensi.

\section{PEMBAHASAN}

Hasil penelitian menunjukan bahwa dari 100 responden sebagian besar (67.0\%) responden mengalami hipertensi. Hal ini menunjukan bahwa pasien yang berobat di Poliklinik jantung RSUD Dr. M.Yunus Bengkulu banyak yang mengalami hipertensi. Hipertensi adalah penyakit yang bisa menyerang siapa saja, baik yang muda maupun tua, orang kaya maupun orang miskin. Hipertensi adalah suatu penyakit mematikan di dunia yang biasa dikenal dengan silent killer atau pembunuh diamdiam. Hipertensi tidak langsung dapat membunuh penderitanya, melainkan dapat memicu terjadinya penyakit lain yang tergolong kelas berat seperti serangan jantung, gagal jantung, stroke dan gagal ginjal. Hingga saat ini upaya untuk mencegah maupun mengobati penyakit hipertensi belum berhasil sepenuhnya, karena adanya faktorfaktor penghambat seperti kurang pengetahuan tentang hipertensi (Adib, 2009).

Pencegahan hipertensi dapat dilakukan dengan memperhatikan beberapa hal: Perubahan gaya hidup bisa membantu mengendalikan tekanan darah tinggi. Perubahan gaya hidup dan obat-obatan bisa menurunkan tekanan darah tinggi sampai pada batas normal dengan olahraga dan mempertahankan berat badan normal, olahraga yang teratur dapat membantu menurunkan berat badan (Adib, 2009).

Hasil penelitian menunjukan bahwa dari 12 responden yang mengalami obesitas terdapat 11 responden $(91.7 \%)$ yang mengalami hipertensi dan dari 88 responden yang tidak obesitas terdapat 56 responden (63.3\%) yang mengalami hipertensi. Hal ini menunjukan hipertensi primer adalah hipertensi esensial atau hipertensi yang tidak diketahui penyebabnya. Beberapa faktor yang diduga berkaitan dengan hipertensi esensial diantarnya: Genetik, jenis kelamin dan usia, diet misalnya diet tinggi garam dan tinggi kandungan lemak, berat badan berlebih (obesitas), gaya hidup yang tidak sehat seperti merokok dan konsumsi alkohol (Ardiansyah, 2012).

Obesitas dapat menambah beban kerja jantung dan pembuluh darah. Kelebihan lemak dapat menambah kongesti vena. Orang yang obes cenderung untuk tidak melakukan kegiatan fisik, mengalami penyakit diantaranya hipertensi, hiperlipidemia atau peningkatan lipid seperti trigliserida dan kolesterol dapat membentuk plak-plak atreosklerotik dalam pembuluh darah arteria, penyumbatan ini akan memperkecil lumen pembuluh darah dan mempercepat aliran darah sehingga meningkatkan tekanan darah (Baradero, 2008).

\section{KESIMPULAN}

Berdasarkan hasil penelitian dan pembahasan yang telah dilakukan dapat diambil kesimpulan sebagai berikut:

Sebagian besar pasien di poliklinik Jantung (67.0\%) mengalami hipertensi dan 
sebagian kecil pasien di poliklinik Jantung (12.0\%) mengalami obesitas, ada hubungan antara obesitas dengan kejadian hipertensi dengan nilai $\mathrm{P}=0,000$.

\section{SARAN}

1. Bagi Ruangan Poliklinik Jantung RSUD Dr.M.Yunus Bengkulu

Kepada pihak rumah sakit diharapkan dapat meningkatkan program penyuluhanpenyuluhan yang lebih baik lagi kepada pasien maupun kepada keluarga pasien mengenai faktor-faktor penyebab hipertensi terutama obesitas sehingga pasien akan berusaha mengatur diit yang sehat dan menjaga kestabilan $\mathrm{BB}$, selalu mengingatkan penderita hipertensi untuk selalu mengontrol tekanan darahnya setiap hari.

\section{Bagi Peneliti Selanjutnya}

Hasil penelitian ini bisa digunakan sebagai bahan tambahan referensi apabila dilakukan kembali penelitian yang serupa menyangkut faktor-faktor yang dapat menyebabkan terjadinya penyakit hipertensi yang lebih spesifik, menggunakan jumlah sampel yang lebih besar dan dengan metode penelitian analitik dibandingkan dengan penelitian ini.

\section{DAFTAR PUSTAKA}

Ardiansyah, Muhamad. 2013. Medikal Bedah Untuk Mahasiswa. Diva Press: Jakarta.

Dinas Kesehatan Propinsi Bengkulu. 2012. Profil Promosi Kesehatan Propinsi Bengkulu Tahun 2012 Bengkulu.

Hawari, Dadang. 2004. Penyakit Kardiovaskuler Dimensi Psikoreligi. Gaya Baru: Jakarta.

Riwidikdo, Handoko. Statistik Kesehatan Belajar Mudah Teknik Analisis Data Dalam Penelitian Kesehatan (Plus Aplikasi Sofware SPSS). Media Cendikia Press: Yogyakarta.

Suddarth. 2000. Keperawatan Medikal Bedah
Edisi 8 Volume 8. EGC: Jakarta.

Sabri, Luknis dan Sutanto Priyo Hastono. 2010. Statistik Kesehatan. Raja Grafindo Persada: Jakarta

Santjika, Aris. Statistik Untuk Penelitian Kesehatan 1. Nuha Medika: Yogyakarta.

Supriyanto, Agus. 2009. Obesitas, faktor penyebab dan bentuk-bentuk therapinya. diakses http:www journaldok.co.id tanggal 29 Desember 2013.

Valery. 2007. Stroke. Media Auskulpius: Jakarta.

Yufita, yeni dkk. 2009. Faktor - Faktor Yang Berhubungan Dengan Kejadian Hipertensi Pada Wanita Usia Subur Di Puskesmas Umbulharjo I Yogyakarta [Skripsi] Fakultas Ilmu Kesehatan Masyarakat Universitas Ahmad Dahlan. Jurnal Kesmas diakses http://wwwjurnalkesmasuad.co.id tanggal 02 Jnauari 2014. 